REsumo
O presente trabalho discute a
particularidade da escuta que
pode ser oferecida à singulari-
dade do sujeito na instituição de
saúde mental, por meio da aná-
lise de um fragmento clínico que
evidencia a dificuldade da escu-
ta do sujeito em um contexto de
precariedade da rede de atendi-
mento à saúde mental. Proble-
matiza-se, assim, a questão do
encaminhamento que, ao invés
de promover saidas para o caso,
encerra tais possibilidades, pro-
curando uma solução sem a ofer-
ta de um espaço de escuta para
o sujeito.
Descritores: psicanálise; su-
jeito; rede de saúde mental; a
escuta psicanalitica.

\section{UM OLHAR SINGULAR: A CLÍNICA NA INSTIITUIÇÃO DE SAÚDE MENTAL}

\author{
Gabriela Rinaldi Meyer \\ Manoel Tosta Berlinck
}

\section{Introdução}

A ideia de escrever este trabalho surgiu a partir da escuta da história de um menino de 4 anos, relatada por sua mãe, em um único atendimento realizado em um Centro de Atenção Psicossocial infantojuvenil (CAPSi) de São Paulo. Este atendimento, por formalidade, o primeiro que é oferecido a quem chega ao CAPS, é nomeado "acolhimento". Cada instituição tem a liberdade de nomear como

Psicanalista, Pós-doutoranda pelo Laboratório de Psicopatologia Fundamental - Pontifícia Universidade Católica de São Paulo (PUC/SP).

Sociólogo, psicanalista, Professor aposentado da Universidade Estadual de Campinas (UNICAMP, Campinas, SP), Professor do Programa de Estudos Pós-Graduados em Psicologia Clínica da Pontifícia Universidade Católica de São Paulo (PUC-SP). 
melhor entender este primeiro momento de contato com o paciente. Em outro CAPS, esse atendimento foi nomeado "recepção" e em outros dispositivos, principalmente naqueles anteriores ao movimento da reforma psiquiátrica no Brasil, costumava-se nomear tal atendimento como entrevista de "triagem". Herança que se mantém em muitos serviços que surgiram a partir da reforma psiquiátrica.

O primeiro encontro com um caso, muitas vezes único, é importante, pois é o momento em que se tenta identificar o motivo que o levou até ali. Tales chegou com um diagnóstico pronto e foi isto que logo chamou a atenção. Ele parecia dar muito trabalho na escola e em casa. Ao escutar o que era dito por sua mãe, Júlia, uma questão de imediato fez-se presente: que caminho oferecer para tal encaminhamento? Como se posicionar diante de um diagnóstico fechado classificando uma criança de 4 anos como uma criança que oferece perigo aos que estão a sua volta? É justamente sobre isto que este trabalho pretende discursar, problematizando algo que está muito presente nas instituições que tratam de crianças: o excesso de diagnóstico que demanda prescrição medicamentosa como uma solução para o problema da escola, da família e, muitas vezes, até das próprias instituições que deveriam atender, mas não dão conta de fazê-lo e procuram na medicação um suporte. Como enfrentar tal problema?

\section{Fragmento clínico}

Tales, um menino de 4 anos, chegou para um atendimento em um Centro de Atenção Psicossocial infantojuvenil (CAPSi), trazido por sua mãe já cansada de procurar ajuda e "não resolver o problema”. Eles foram encaminhados por uma Unidade Básica de Saúde, instituição que acompanhava o caso que lhe foi encaminhado pela escola. As poucas palavras ditas pela mãe expressavam seu abatimento e sua ignorância em relação à situação. Ao ser convidada a falar, Júlia começou a contar a história do filho: "Desde que nasceu é desafiador, não aceita limites, ninguém pode com ele! O irmão mais velho acaba sendo prejudicado, pois tem que ceder sempre." Como assim? "É doutora, nós nunca demos limites a ele porque ele é muito genioso, temperamental; ele far. o que quer e consegue tudo o que quer." Estas palavras são de uma mãe 
que embora reconheça suas dificuldades na relação com o filho, não consegue contorná-las ou até enfrentá-las. Tal situação evidencia o quanto esta mulher está precisando ser acolhida e escutada.

Ao escutar a fala de Júlia, me perguntei sobre a natureza do encaminhamento para uma instituição como o CAPS, já que esta, pelas diretrizes do Ministério da Saúde, trata de crianças e jovens com graves transtornos mentais, os chamados autistas, psicóticos e neuróticos graves. Júlia demonstrava não saber o motivo de tal encaminhamento, repetindo o que estava escrito no papel em suas mãos: "solicito avaliação psiquiátrica". Ao dar continuidade ao relato da história do filho, mostra-se bastante aflita com a dificuldade que tanto ela quanto seu marido têm em colocar limites a ele. O pai faz tudo para não desagradálo, atendendo a todos os seus pedidos. Isto faz de Tales um menino exigente e agressivo, o que fica evidente na escola.

Durante o atendimento, Tales permaneceu um curto tempo na sala, momento em que a escuta da fala da mãe dividia-se com a tentativa de incluí-lo na conversa, o que na maioria das vezes era inútil, pois ele negavase a participar, escolhendo concentrar-se nos brinquedos presentes na sala. A outra parte do tempo ele permaneceu na sala de espera com os profissionais responsáveis pelas crianças nessa sala. Apesar de não querer participar diretamente, o tempo todo 
estava ali a escutar o que estava sendo dito a seu respeito e isso era pontuado para ele. No final, aconteceu um episódio que evidenciou claramente o que trazia a mãe: Tales pegou o celular da mãe para brincar (ela deu a entender que isso acontece frequentemente) e esta disse que não podia; ele continuava a agir; ela, nervosa, tentava tirar o objeto da mão do filho, mas não conseguia. Ao observar a cena, decidi intervir ajudando-a a dizer não para o filho. A mãe ficou muito constrangida, envergonhada, humilhada. Por fim, conseguiu tirar o celular da mão dele que, imediatamente, começou a chorar e a berrar. Chorou muito, de forma desesperada e ela cedeu. Intervindo mais uma vez, aproximei-me dele esclarecendo que o celular não era brinquedo e que ele podia brincar com outras coisas. Abraçei-o, oferecendo continência para que ele se acalmasse e pudesse ouvir. Ele se acalmou e escutou.

A cena composta pelo relato materno e pela interlocução mãe e filho permitiu-nos observar, claramente, que Tales precisava mais de limites do que de atendimento psiquiátrico. E agora, aos 4 anos, reclamava por estes limites veementemente por meio de uma comunicação invertida. O que fazer diante disto?

O quadro "pintado" nos leva a pensar no quanto essa família precisa de tratamento; Tales aparece na cena como o foco do problema; problema, segundo a mãe, de "gênio forte".
Caracterizá-lo como genioso serve como defesa para os pais, na medida em que não permite que eles de fato enxerguem o problema. Por isso é necessária a presença de alguém de fora que possa ocupar aí outro lugar, ajudando-os a olhar o que se passa na relação com o filho. Não podemos pensar em um tratamento do infantil sem incluir os pais, como fica claro nas palavras de Levy (2008) ${ }^{1}$ :

É a partir da demanda, trazida com freqüência pelos pais, que pode ser encarado o modo como é constituído o sintoma na criança. De fato, levantaremos a hipótese que o sintoma é uma resposta da criança construída a partir da angústia de um dos pais, ou dos dois, resultante da posição ideal infantil e parental. Entendemos com isso a posição que leva cada um dos pais à própria castração, na idéia de uma inter-relação entre o sintoma da criança e o dos pais que o levam para a consulta (Levy, 2008, p. 59).

Isto faz lembrar o caso do pequeno Hans tratado por Freud (1909/ 1996b) por intermédio do pai: era ele que levava ao analista tudo que observava em relação à fobia do filho. Este pai teve uma participação fundamental no processo de tratamento do filho. Freud não tratou diretamente de crianças, mas sim do infantil que existe no adulto, focando-se no que poderia constituir-se como etiologia das neuroses. O caso do pequeno Hans foi uma exceção, que muito auxiliou Freud em suas pesquisas sobre o infantil. É desta forma que privilegia a infância como o momento no qual as principais marcas se consti- 
tuem, trazendo uma ideia que foi muito repudiada na época, a ideia de que a sexualidade é infantil e é justamente a curiosidade a respeito da sexualidade que impulsiona a criança a tornar-se um pequeno pesquisador, como observamos na passagem:

Ao mesmo tempo em que a vida sexual da criança chega a sua primeira florescência, entre os 3 e os 5 anos, também se inicia nela a atividade que se inscreve na pulsão de saber ou de investigar. ... Suas relações com a vida sexual, entretanto, são particularmente significativas, já que constatamos pela psicanálise que, na criança, a pulsão de saber é atraída, de maneira insuspeitadamente precoce e inesperadamente intensa, pelos problemas sexuais, e talvez seja até despertada por eles. (Freud (1905/1996a) p. 183). ${ }^{2}$

São os interesses práticos e não os teóricos que estimulam a atividade investigatória da criança, sendo o primeiro problema com o qual se depara que a torna pensativa e perspicaz, o que se dá em consonância com o despertar da pulsão de saber, por intermédio do enigma: de onde vêm os bebês? De onde eu vim?

Em seu caminho em direção à descoberta do inconsciente, Freud perguntava-se por que o período da infância muitas vezes não é lembrado pelo adulto? Ou melhor, por que será que ele está facilmente sob a influência do recalque?

Ao escutar a fala de Júlia, continuei a me questionar a respeito de qual seria a direção de um tratamento para Tales. Será que o CAPS seria o espaço adequado para acolhê-lo? Essa pergunta nunca se afasta de nossos horizontes quando fazemos o primeiro atendimento em um Centro de Atenção Psicossocial, pois neste momento precisamos entender do que se trata para fazer o melhor encaminhamento. Mas não era só este motivo que fazia questão. $\mathrm{O}$ que preocupava era o sofrimento desta criança de apenas 4 anos e desta família, tão perdida, sem norte e sem parâmetros. Júlia não sabia nem como pedir ajuda, e estava ali porque preferia acreditar que seu filho precisava de medicação, já que nada o continha. Ao mesmo tempo, parecia muito assustada com a ideia de dar ao filho remédios tão fortes, como estes que são ministrados para as crianças com diagnóstico de hiperatividade ou de transtorno de comportamento generalizado. Esse medo, no entanto, não a fazia agir no sentido contrário, pois acreditava que, se foi encaminhado para uma avaliação psiquiátrica, é porque era esse o caminho a seguir.

Tal encaminhamento é questionado porque tem como base a aparente dificuldade enfrentada pela equipe que acompanhava o caso 
de escutar o sofrimento desta família. Assim, ao invés de encaminhá-lo para o CAPS na tentativa de pedir ajuda, solicitando um trabalho em parceria, encaminharam-no com um diagnóstico já pronto, fechado, com palavras de desesperança e de pouco investimento e aposta em sua subjetividade. Tal encaminhamento foi entendido como algo que já traçava um destino para este menino. Não solicitavam apenas uma avaliação psiquiátrica, mas sugeriam que ele precisava de fato de um atendimento psiquiátrico, pois não acatava ordens, não aceitava limites, e tornava-se a cada dia mais violento na escola. Estava, inclusive, correndo o risco de receber um $\mathrm{BO}$ (boletim de ocorrência) por violência e ser expulso da escola. Precisavam contê-lo. Será um menino de 4 anos assim tão assustador? O que os impede de ouvi-lo? O que os impede de escutar o relato de sua mãe?

Neste ponto, é importante chamar a atenção para a questão a respeito dos encaminhamentos e das diretrizes clínicas e políticas que definem os casos que devem ser acolhidos nos CAPS de forma geral. Tais diretrizes são gerais e não levam em conta a singularidade, o que pode perturbar a escuta dos trabalhadores de saúde mental. Quando recebemos um caso, de acordo com as diretrizes, é necessário direcionar a escuta com base nos diagnósticos classificatórios que definem quem se trata ou não nos CAPS. Corremos, desta forma, o gra- 
ve risco de ficarmos surdos ao que nos diz o sujeito com seu sofrimento. Tal dificuldade de escuta torna-se evidente, particularmente, neste primeiro momento de acolhimento de quem chega à instituição, momento de decisão de como encaminhar o caso. Como bem deixa claro Elia, Costa e Pinto no texto: "Sobre a inserção da psicanálise nas instituições de saúde mental (2005), trata-se de uma dificuldade sempre presente na clínica que se desenvolve na instituição de saúde mental - a de escutar o sujeito:

Uma das maiores dificuldades dos profissionais que trabalham no campo da saúde mental é escutar o sujeito. Muitas vezes eles são atropelados pela via humanista, que é naturalizada por muitos profissionais que ficam presos a um certo ideal de um bem a ser alcançado por um paciente. Acentua-se uma preocupação com o campo do social ensurdecendo uma outra escuta que nos parece fundamental: a da posição desse sujeito. ... Entender a importância dessa dimensão, de tomar essa escuta do sujeito como direção de todo o trabalho, marca uma diferença fundamental entre a psicanálise e os outros saberes, uma vez que nem mesmo a dimensão burocrática pode prescindir da clínica, seja ela qual for (Elia, Costa e Pinto, 2005, p. 133).

Ao sustentarmos nossa disponibilidade de escuta podemos pensar que Tales é um caso para atendimento psicoterápico ou psicanalítico, dentro ou fora do CAPS, no entanto, em um primeiro momento, não se trata de um caso para ser medicado. Uma coisa é bem diferente da outra, embora com frequência os profissionais, ao encaminharem um caso para o CAPS, encaminham-no para a psiquiatria buscando uma solução por meio da medicação, como se CAPS fosse sinônimo de medicação. É neste sentido que precisamos desconstruir essa ideia e construir algo novo no que diz respeito ao acolhimento e tratamento dos sujeitos dentro ou fora dos CAPS. Isto não significa excluir a psiquiatria como parceira neste trabalho de acolhimento e tratamento de casos graves, muito pelo contrário, a ideia é incluí-la, mas de uma forma que não reafirme o lugar, já presente no imaginário da população em geral, de que vai resolver todos os problemas isoladamente, fazendo da utilização da medicação uma resposta tampão, uma espécie de "solução mágica".

O caso de Tales, apesar de não ser considerado ou supostamente diagnosticado como um caso de psicose ou de autismo, não deve ser excluído da possibilidade de ser tratado, pois ele e os pais precisam de ajuda. $O$ fato de não ser um caso de psicose ou de autismo, pode levar a pensar não se tratar de um caso grave. Será? Como avaliar essa gravidade? Isso nos faz refletir sobre os referenciais de gravidade presentes nas diretrizes da política de saúde mental, que definem os casos que devem ser tratados nos CAPS. Entretanto, é importante ampliarmos nosso poder de escuta para identificarmos casos "não graves" que, se não tratados, podem tornarse graves. 
Este quadro clínico indica-nos muito bem o quanto as crianças têm sido vítimas de diagnósticos estigmatizantes que, ao invés de conduzirem à direção do tratamento, fecham portas, ultrapassando o sujeito que se manifesta ora pelo sintoma (no caso da neurose) ora pelo delírio ou pelo completo isolamento (no caso da psicose e do autismo).

O fragmento clínico apresentado é interessante na medida em que expõe tal problemática e nos faz pensar quais as consequências que isso tem para a clínica e para a infância no mundo atual.

\section{Como olhar para a criança? Algumas considerações teóricas}

No início, a partir do nascimento, o bebê situa-se em uma posição de não diferenciação em relação à mãe, seu primeiro outro/Outro. Freud (1925/1996d) menciona a questão da diferenciação entre o egoprazer original e o mundo externo de forma bastante interessante no texto A negativa, onde pontua a importância da negação e da afirmação para a constituição da subjetividade. O dentro e o fora, a princípio indiferenciados, precisam ser demarcados para o bebê e isso se dá pela fala da mãe, do outro/Outro, ou seja, pela linguagem. Assim, a imagem de si, o ego, vai delimitando-se, definindo-se, até o mo- 
mento em que o bebê se vê como imagem no espelho, como um. Isto se dá a partir da intervenção do Outro, que vem de fora. Este momento Lacan (1998a) bem definiu como o estádio do espelho. Retomando Freud no texto citado acima, observamos sua preocupação com a negação (Verneinung) e com a afirmação (Bejahung) ${ }^{4}$. Em suas palavras:

negar o conteúdo de pensamentos é tarefa da função do julgamento intelectual. ... Negar algo em julgamento é, no fundo dizer: 'Isto é algo que eu preferia reprimir' .... O atributo sobre o qual se deve decidir pode originalmente ter sido bom ou mau, útil ou prejudicial. Expresso na linguagem dos mais antigos impulsos instintuais - os orais -, o julgamento é: ... 'gostaria de botar isso para dentro de mim e manter aquilo fora’... O ego-prazer original deseja introjetar para dentro de si tudo quanto é bom, e ejetar de si tudo quanto é mau. Aquilo que é mau, que é estranho ao ego, e aquilo que é externo, são, para começar, idênticos (Freud, 1925/1996d, p. 266-267).

No início, para o ego, nada é estranho e, a distinção entre o estranho e o si-mesmo é uma operação, digamos, de expulsão. Para se diferenciar do outro, a criança precisa do não e do sim, mas antes, do não, da expulsão. Precisa excluir algo para, em um momento posterior afirmar o que lhe é próprio. Hyppolite ${ }^{5}$ (1989) pontua isto ao tecer comentários sobre o texto de Freud supracitado:

Freud acabara de dizer que se introjeta e se expulsa, que existe então uma operação que é a operação de expulsão [sem a qual] a operação de introjeção [não teria sentido]. É a operação primordial onde aquilo que será o julgamento de atribuição [se funda] (Hyppolite, 1989, p. 53).

Lacan (1998b), no texto "De uma questão preliminar a todo tratamento possível da psicose" (1957-1958), estando às voltas com a teoria da foraclusão do Nome-do-Pai, caracteriza a Bejabung como uma primeira afirmação, colocando-a em relação com a $V$ erverfung, como afirma: "A Verwerfung se articula nesse registro como a ausência de Bejabung, ou juízo da atribuição, que Freud postula como precedente necessário a qualquer aplicação possível da Verneinung, que ele lhe opõe como juízo de existência." (Lacan, 1998b, p. 564).

A partir da ideia de que a criança precisa expulsar algo, ou seja, negar algo, para poder afirmar e se afirmar como sujeito, como podemos pensar a questão levantada pelo fragmento do caso? Tal questão nos leva a questão atual de ausência de limites, identificada pela escola e encaminhada para a clínica. O que tem se observado aí 
é uma tendência dos pais apresentarem-se perdidos, não sabendo como educar, colocar limites e até expressar seu amor pelos filhos. Sentem-se incapazes de dizer não porque quando tem tempo para estar com os filhos, não querem frustrá-los e sim compensar sua ausência. Neste sentido frustrar os filhos gera uma intensa culpa, o que é insuportável.

Como efeito disto, as crianças sofrem pela ausência afetiva, ausência de olhar, recebendo tudo o que querem como compensação para a falta maior, que não pode ser suprida materialmente. A frustração é fundamental para a organização da criança, como deixa claro Lacan ${ }^{6}$ quando enfatiza que a estruturação do sujeito se dá em função de uma ausência e não de uma presença. Quando o bebê nasce, durante um tempo ele vive a ilusão de que completa a mãe e esta, embora saiba que isso é uma ilusão, aproveita para também se iludir. No entanto $^{7}$, ela, aos poucos, vai transmitindo ao bebê que, embora ele seja muito importante, ela tem também outros interesses - esse é o momento de abertura para a entrada de um terceiro na relação, o pai. Esse desvio de olhar da mãe para o pai e para o mundo é necessário para que a criança se organize, sendo essa primeira experiência de separação a que coloca a criança diante da falta. Essa mensagem vem do Outro representado pelo outro materno. O bebê humano é bastante "imaturo", precisa do outro; outro que cuide dele e aju- de-o a se organizar. É o toque da mãe ou do pai, que oferece o contorno do corpo para o bebê. Isso se dá pela linguagem - é a fala que faz do humano vivo, tornando cada parte do corpo pulsante, o que é fundamental para o bebê se constituir como sujeito.

Freud (1920/1996c) tratou da questão da simbolização da ausência da mãe ao referir-se a uma brincadeira experimentada por seu neto e observada por ele. Foi em Além do princípio do prazer que ele descreveu essa brincadeira e tirou suas conclusões. A criança em questão tinha o hábito, desde 1 ano e meio de idade, de atirar longe seus objetos e, a cada vez que fazia isto, emitia um som "O-O-O-Ó". Freud, junto à mãe da criança, deduziu que este som representava a palavra alemã 'fort' que significa 'ir embora". Neste momento, acabou por compreender que se tratava de um jogo e este era o uso que a criança fazia de seus brinquedos, brincar de mandá-los embora. A brincadeira completa foi observada quando a criança utilizou um carretel e, após arremessá-lo para longe e fazê-lo sumir, puxava-o novamente para sua direção, saudando-o com a expressão "da" (“ali"), resumindo-se em desaparecimento e retorno. Isto tinha intensa relação com as idas e vindas da mãe. A primeira parte da brincadeira repetia-se constantemente, mas era no segundo ato que a criança esboçava constante prazer, momento em que a mãe retornava. 
Tal jogo é a forma que a criança encontrou para simbolizar a ausência materna. A ausência da mãe aponta para o fato de que o desejo dela se direciona para outra coisa que não só para a criança. Neste sentido, a mãe é presente, mas também ausente. $\mathrm{O}$ falo é o significante das idas e vindas da mãe, e é isso que permite a entrada do pai num momento posterior, abrindo caminhos para a constituição de um sujeito que é atravessado pela falta. É o pai como significante que vem simbolizar o falo, o que permite simbolizar a falta, a castração, pois o falo é o significante que aponta para a castração.

A dificuldade da mãe de Tales em lidar com a falta e de colocar limites faz com que ele fique frágil diante de situações que o coloquem diante da falta. Situações estas presentes cotidianamente a partir da relação com o Outro, seja na escola, na rua ou em casa.

Muitos dos problemas escolares identificados atualmente podem ser caracterizados como uma forma específica de comunicação da criança com o mundo adulto dentro e fora da escola. Digo atualmente porque isso tem aparecido frequentemente na clínica: uma demanda da educação que transborda para fora deste espaço, comunicando-se com a saúde mental, como bem apresenta o fragmento clínico citado. Os sintomas observados aí, tais como distúrbios da aquisição da linguagem, atrasos na fala, dificuldades de aprendizagem, 
hiperatividade e déficit de atenção, entre outros, definem uma forma bastante particular de comunicação. A maturidade psíquica para elaboração da fala sobre os sentimentos ainda não está presente na infância, assim, é fazendo sintoma que a criança fala sobre si.

Desta maneira, os pais, tal como a sociedade, começam a olhála e é mais precisamente na escola que isso chama atenção, pois a escola é o meio social da criança fora da família. Entretanto, é importante estarmos atentos para o fato de que "a formação do sintoma é uma interpretação inexata do sujeito" (Lacan, 1998c, p. 599). É preciso escutar o que as crianças nos dizem com o sintoma, para nos direcionarmos à escuta do sujeito. A partir do caso descrito, observamos como Tales responde à falta de limites que não recebe dos pais, tornando-se agressivo, descontrolado, pedindo ajuda deste jeito, que é o que ele encontra como uma comunicação possível. Desta forma, acaba sendo classificado, como muitas outras crianças, de hiperativo ou portador de um transtorno de comportamento. Isto o determina para sempre, marcando-o, categorizando-o, fechando portas para outras possibilidades.

Pensando a instituição como uma estrutura simbólica que insere a criança no mundo, é importante acentuar que estamos tratando neste texto de três níveis institucionais: a família, a primeira delas, a escola e a instituição de saúde mental. Tales chegou a instituição de saúde mental porque a família e a escola não estão dando conta de escutar o que se passa com ele. Neste sentido, o interessante é nos perguntar de que forma o CAPS, como uma instituição, pode acolher e escutar o sujeito que sofre? Isto nos faz lembrar o que sugere Di Ciaccia no texto "A criança e a instituição" (2005), quando diz que:

não existe criança sem instituição: esses dois termos estão ligados. Sem dúvida, podem concordar ou se opor, estar em harmonia ou em discordância, articular-se dialeticamente ou holofrasear-se. Mas o primeiro termo implica necessariamente o segundo. E por mais de uma razão. ... não existe criança sem instituição porque a instituição é um efeito do simbólico sobre o homem. Graças ao simbólico, que ganha forma no complexo de Édipo, a criança se humaniza, isto é, torna-se sujeito do inconsciente - independentemente de sua estrutura, neurótica, perversa ou psicótica, ela realiza sua inserção pessoal e particular no mundo humano (Di Ciaccia, 2005, pp. 19-22). 


\section{Ser hiperativo ou ser menino maluquinho?}

Tal como o menino maluquinho, personagem de Ziraldo (2008), Tales quer brincar, se aventurar, correr, fantasiar e se expressar. Com "fogo no rabo e vento nos pés" (Ziraldo, 2008. pp. 9-10) chega à escola chamando a atenção dos que estão por perto. Estes, já habituados com o mundo contemporâneo em que as crianças não podem ser crianças, têm que se comportar como adultos, não toleram o comportamento agitado de Tales. Mas, não foi sempre assim. Há tempos eram permitidas maior liberdade e tolerância às crianças. $\mathrm{O}$ menino maluquinho era chamado de maluquinho justamente porque era livre, tinha "vento nos pés e macaquinhos no sótão (embora nem soubesse o que significava macaquinhos no sótão)" (Ziraldo, 2008, pp. 9-12). Como indica Ziraldo (2008), ele era um menino impossível e muito sabido. Em suas palavras:

A melhor coisa do mundo na casa do menino maluquinho era quando ele voltava da escola. A pasta e os livros chegavam sempre primeiro voando na frente. Depois entrava o menino com seu pé de vento e a casa ventava os quartos cantavam e tudo se enchia de som e alegria. E a cozinheira dizia: "chegou o menino maluquinho" (Ziraldo, 2008, p. 29-31).

Ser livre não significa não ter limites; estes precisam existir inclusive para que a liberdade aconteça. Esses limites vêm de fora, do Outro, e são fundamentais para que a criança possa constituir seus próprios limites, começando pelos limites de seu próprio corpo.

Uma criança que não recebe os limites dos pais, sente-se insegura, sendo colocada frente a frente com um desamparo sem tamanho. O desamparo, a falta, são constitutivos do humano, portanto não há relação que não seja marcada por isto, contudo, o que é interessante acentuar aqui é a dimensão que pode tomar o desamparo para a criança quando esta se vê abandonada pela falta de limites. E aí, faz sintoma. Neste caso, podemos pensar que um comportamento pode ser considerado sintomático quando ele se torna excessivo.

Parece que é isso que ocorre com Tales, quando repete excessivamente um comportamento agressivo e agitado, pedindo, em ato, limites. A equipe que estava a frente de seu atendimento na Unidade Básica de Saúde (UBS), assim como os pais, não conseguiram escutar seu pedido, encontrando na medicação uma solução. É justamente isto que queremos questionar: será que precisamos categorizar Tales e estigmatizá-lo com uma sigla classificatória? Talvez, o menino maluquinho, hoje, também fosse considerado hiperativo, um menino com problemas de comportamento, mas justamente indo na contramão disto, Ziraldo (2008) nos conta que ele era um menino que sabia brincar 
com o tempo e este era seu maior mistério:

o seu maior mistério todos sabiam de cor: era o jeito que o menino tinha de brincar com o tempo. Sempre sobrava tempo pra fazer mil traquinadas e dava tempo para tudo. $\mathrm{O}$ tempo era um amigão. Seu ponteiro das horas vai ver era um ponteirão. E sobrava tempo para ler os gibis e sobrava tempo para colar figurinhas e para anotar nos livros de histórias e aventuras todas aquelas passagens em que ele virava o herói. O tempo era assim para ele: fazia horas a mais. (Ziraldo, 2008, p. 77-83).

Antes de categorizar Tales, torna-se necessário escutá-lo, prestar atenção a seu pedido de ajuda que não tem sido valorizado pelas instituições de saúde por onde passou. Sua mãe, igualmente, precisa ser escutada, pois carrega um sofrimento quase que conformado, acomodado, resignado. Fica apavorada diante do comportamento do filho e cede, sempre, para não enfrentá-lo ou para não enfrentar a si mesma e entrar em contato com suas angústias.

Introduzimos, nesta parte, uma analogia com a história do menino maluquinho por considerar tal personagem um exemplo vivo do que seria uma criança categorizável nos moldes das siglas classificatórias utilizadas de forma excessiva atualmente. ${ }^{9}$ E, ao contrário, ele foi considerado um menino saudável, que tinha muitos amigos e era muito querido e amado pelas pessoas que estavam a sua volta. Quando ele não estava em casa, inclusive, esta ficava vazia, sem gra- 
ça, sem alegria. E, mesmo tendo o tempo como seu aliado, não conseguiu segurá-lo e deixou que este passasse. O tempo passou e ele cresceu e transformou-se num homem muito bacana, especial. Como nos conta Ziraldo, ele "cresceu e virou um cara legal! Aliás, o cara mais legal do mundo! Mas um cara legal mesmo! E foi aí que todo mundo descobriu que ele não tinha sido um menino maluquinho... Ele tinha sido era um menino feliz! (Ziraldo, 2008, pp. 102, 104107).

E por que não apostar em Tales? Por que não apostar em todas as crianças que estão a nos pedir ajuda, a nos pedir limites, a nos pedir escuta?

Retomando a questão problematizada, aquela do encaminhamento que, ao invés de promover saídas para o caso, encerra tais possibilidades, procurando uma solução sem a oferta de um espaço de escuta para o sujeito, é necessário estarmos atentos para o quanto isso tem acontecido em todos os dispositivos que tratam de crianças, sejam as instituições de saúde ou de educação. Há aí, como dito, um entrecruzamento de demandas que nos convoca, como trabalhadores de saúde mental, à realização de uma possível mediação entre a escola, as instituições de saúde e os pais. Que lugar para Tales na família, na escola, na sociedade? 
A SINGULAR VIEW: THE CLINICAL IN THE MENTAL HEALTH ORGANIZATION

\section{Abstract}

This paper discusses the particularity of listening, which can be offered to the singularity of the person in the mental health organization, through the analysis of a piece of a clinical case that highlights the difficulty of listening to the person in the context of the mental health organizations' precariousness. It questions the proceeding that, instead of advancing solutions to the situation, closes possibilities, proposing solutions that do not include the offer of a listening space to the person.

Index terms: psychoanalysis; subject; mental health organizations; psychoanalytical listening.

UNA MIRADA SINGULAR: LA CLINICA EN LA INSTITUICIÓN DE SALUD MENTAL

\section{RESUMEN}

Ese estudio discute las particularidades de la escuch a que puede ser ofrecida a la singularidad del sujeto en la institución de salud mental, por medio del análisis de un fragmento clínico que destaca la dificultad de la escucha de un sujeto en un contexto de precariedad de la red de atendimiento a la salud mental. Cuestionase, por lo tanto, el tema del encaminamiento que, en lugar de fomentar soluciones para el caso, encierra tales posibilidades, buscando una solución sin oferta de un espacio para la escucha del sujeto.

Palabras claves: psicoanálisis; sujeto; instituciones de salud mental; escucha psicoanalitica.

\section{REFERÊNCIAS}

Di Ciaccia, A. (2005). A criança e a instituição. In S. Altoé \& M. Mello de Lima, Psicanálise, Clínica e Instituição. Rio de Janeiro: Rio Ambiciosos.

Elia, L., Costa, R. \& Pinto, R. F. (2005). Sobre a inserção da psicanálise nas instituições de saúde mental. In S. Altoé \& M. Mello de Lima, Psicanálise, Clínica e Instituição. Rio de Janeiro: Rios Ambiciosos.

Freud, S. (1996a). Três ensaios sobre a teoria da sexualidade. In S. Freud, Edição standard brasileira das obras psicológicas completas de Sigmund Freud (J. Salomão, trad., Vol. 7, pp. 119-231). Rio de Janeiro: Imago. (Trabalho originalmente publicado em 1905).

Freud, S. (1996b). Análise de uma fobia em um menino de cinco anos. In S. Freud, Edição standard brasileira das obras psicológicas completas de Sigmund Freud (J. Salomão, trad., Vol. 10. pp. 13-133). Rio de Janeiro: Imago. (Trabalho originalmente publicado em 1909).

Freud, S. (1996c). Além do princípio de prazer. In S. Freud, Edição standard brasileira das obras psicológicas completas de Sigmund Freud (J. Salomão, trad., Vol. 18, pp. 13-78). Rio de Janeiro: Imago. (Trabalho originalmente publicado em 1920). 
Freud, S. (1996d). A negativa. In S. Freud, Edição standard brasileira das obras psicológicas completas de Sigmund Freud (J. Salomão, trad., Vol. 19, pp. 263-272). Rio de Janeiro: Imago. (Trabalho originalmente publicado em 1925).

Hans, L. (1996). Dicionário comentado do alemão de Freud. Rio de Janeiro: Imago.

Hyppolite, J. (1989). Ensaios de Psicanálise e Filosofia. Rio de Janeiro: Taurus-Timbre.

Lacan, J. (1992). O Seminário, livro 17: O avesso da psicanálise, 1969-1970 (A. Roittman, trad.). Rio de Janeiro: Jorge Zahar.

Lacan, J. (1995). O Seminário, livro 4: A relação de objeto, 1956-1957 (Dulce Duque Estrada, trad.). Rio de Janeiro: Jorge Zahar.

Lacan, J. (1999). O Seminário, livro 5: As formações do inconsciente, 1957-1958 (V. Ribeiro, trad.). Rio de Janeiro: Jorge Zahar.

Lacan, J. (1998a). O estádio do espelho como formador da função do eu. In J. Lacan, Escritos (V. Ribeiro, trad., pp. 96-103). Rio de Janeiro: Jorge Zahar.

Lacan, J. (1998b). De uma questão preliminar a todo tratamento possível da psicose. In J. Lacan, Escritos (V. Ribeiro, trad., pp. 537-590). Rio de Janeiro: Jorge Zahar.

Lacan, J. (1998c). A direção do tratamento e os princípios de seu poder. In J. Lacan, Escritos (V. Ribeiro, trad., pp. 591-652). Rio de Janeiro: Jorge Zahar.

Lévy, R. (2008). O infantil na psicanálise - o que entendemos por sintoma na criança. Petrópolis, RJ: Vozes.

Ziraldo, A. P. (2008). O menino maluquinho. São Paulo: Melhoramentos. 


\section{NOTAS}

1 Lévy, R. (2008). O infantil na psicanálise.

2 "Três ensaios sobre a teoria da sexualidade" (1905).

4 Como fica claro em Hanns, no Dicionário comentado do alemão de Freud (1996), o termo Bejahung não é frequente em Freud e sua importância teórica provém do seu uso em contraposicão ao termo Verneinung ("dizer não, "negação", "denegação", "negativa”) (Hanns, 1996, p. 51).

5 Hyppolite, J. Ensaios de Psicanálise e Filosofia, 1989.

6 Seminário 4 (1995): sobre A relação de objeto (1956-1957) e Seminário 5 (1999), sobre As formações do inconsciente (1957-1958).

7 Cabe chamar atenção para o fato de que nem sempre as coisas ocorrem desta maneira. Pode acontecer de a mãe não abrir este espaço para a entrada do terceiro que, por sua vez, também não se coloca. Neste caso, há a possibilidade de ocorrerem outros destinos, como o da psicose.

9 Tais como alguns exemplos citados no início deste trabalho. Não cabe, neste momento, entrar em detalhes neste campo, o que exigiria

gabriela.rinaldi@gmail.com

mtberlin@uol.com.br

Recebido em novembro/ 2010.

Aceito em abril/ 2011. 